\title{
The Mechanism of Radiosensitization by YM155, a Novel Small Molecule Inhibitor of Survivin Expression, is Associated with DNA Damage Repair
}

\author{
Songliu Hua Songbin $\mathrm{Fu}^{\mathrm{b}}$ Xiangying $\mathrm{Xu}^{\mathrm{a}}$ Lin Chen ${ }^{\mathrm{a}}$ Jianyu $\mathrm{Xu}^{\mathrm{a}}$ Bin $\mathrm{Li}^{\mathrm{c}}$ \\ Yuanyuan $\mathrm{Qu}^{\mathrm{a}}$ Hongyang $\mathrm{Yu}^{\mathrm{d}}$ Shan $\mathrm{Lu}^{\mathrm{a}}$ Wenxin $\mathrm{Li}^{\mathrm{a}}$
}

Department of Radiation Oncology, Harbin Medical University Cancer Hospital, Harbin, 'Laboratory of Medical Genetics, Harbin Medical University, Harbin, 'Department of Plastic Surgery, Nanfang Hospital of Southern Medical University, Guangzhou, dThe Second Hospital of Harbin Medical University, Harbin, China

\section{Key Words}

Survivin • Non-small cell lung cancer • DNA repair • DNA-PKcs • Ku70 • Phospho-histone H2AX

\begin{abstract}
Background/Aims: Survivin, a member of the inhibitor of apoptosis protein family, is an attractive target for cancer therapy. We investigated the effects of YM155, a small molecule inhibitor of survivin expression, on the radiosensitivity of human non-small cell lung cancer (NSCLC) cell lines and elucidated a relationship between the cellular localization of survivin and DNA double-strand break repair. Methods: The cellular distribution of survivin was determined by Western blotting of subcellular fractions and by immunofluorescent staining in A549 NSCLC cells. Radiation-induced DNA damage was evaluated based on histone H2AX phosphorylation and foci formation. The relationship between the cellular localization of survivin and DNA double-strand break repair was analyzed by Western blotting and co-immunoprecipitations. Results: YM155 down-regulated survivin expression in NSCLC cells in a concentration- and time-dependent manner. An in vitro clonogenic survival assay revealed that YM155 increased the sensitivity of NSCLC cells to radiation. After irradiation, we observed a rapid accumulation of survivin in the nucleus. An immunofluorescent analysis of histone $\mathrm{\gamma}-\mathrm{H} 2 \mathrm{AX}$ demonstrated that the inhibition of survivin expression by YM155 resulted in impaired DNA double-strand break repair. Co-immunoprecipitation assays using nuclear extracts revealed an interaction between survivin, Ku70, $\mathrm{Y}-\mathrm{H} 2 \mathrm{AX}$, and DNA-PKcs. Furthermore, S2056 autophosphorylation of DNA-PKCS was reduced in survivin-depleted cells. Conclusions: These results suggested that YM155 sensitized NSCLC cells to radiation, at least in part by inhibiting DNA repair and enhancing apoptosis via the down-regulation of survivin expression. YM155 pretreatment inhibited DNA-PKcs autophosphorylation at S2056. Nuclear survivin was involved in DNA

Xiangying Xu

Department of Radiation Oncology, Harbin Medical University Cancer Hospital, Institute of Cancer Prevention and Treatment, Harbin Medical University, No. 150 Haping Road, Nangang District, Harbin, (China); E-Mail husongliu@126.com
\end{abstract}

KARGER 125 
double-strand break repair via interactions with members of the DNA double-strand break repair machinery.

Copyright $@ 2015$ S. Karger AG, Basel

\section{Introduction}

Lung cancer leads to over one million deaths worldwide each year, making it the leading cause of cancer-related death [1]. The clinicopathological characteristics of lung cancer cannot hopefully enable the development of the novel treatment modalities and better prognostic predictors.

Evading apoptotic cell death is critical for tumor growth and is one of the hallmarks of cancer cells that are resistant to anticancer treatment. Therefore, targeting apoptotic pathways may be a promising strategy to counteract resistance and to sensitize cancer cells to anticancer therapeutics, including radiotherapy [2]. Survivin, the smallest member of the inhibitor of apoptosis protein (IAP) family, is a 142 amino acid, $16.5 \mathrm{kDa}$ protein encoded by the BIRC5 gene found at $17 \mathrm{q} 25$ in the human[3]. Survivin is a radiation-resistance factor in numerous human malignances, but the underlying molecular mechanisms appear multifaceted, involving both caspase-dependent and caspase-independent pathways[2]. Chakravarti et al. were the first to report that survivin enhances tumor cell survival after radiation via caspase-independent mechanisms [4]. YM155 is a small-molecule imidazoliumbased compound identified as a selective inhibitor of survivin expression in a highthroughput screen [3]. In phase I clinical trials, YM155 did not exhibit significant toxicity as a single agent. Phase II studies of YM155 as a single agent for certain types of cancer are currently ongoing [5-9].

In mammalian cells, double-stranded DNA breaks (DSB) are repaired by two main pathways-homologous recombination(HR) and non-homologous DNA end-joining(NHEJ) [10]. A key protein in the NHEJ pathway is DNA-dependent protein kinase (DNA-PK). DNAPK is a serine/threonine protein kinase that is composed of a large catalytic subunit, DNAPKcs and a heterodimeric protein, Ku which is composed of a $73 \mathrm{kDa}$ subunit $(\mathrm{Ku} 70)$ and an 86kDa subunit (Ku80) [11]. Current models indicate that the heterodimeric Ku proteins rapidly bind to double-stranded DNA ends and recruit DNA-PKcs, generating a DNA-PK holoenzyme complex. Early in DNA DSB repair, serine 139 of the histone variant $\gamma$-H2AX is phosphorylated by members of the PIKK family, such as ataxia telangiectasia-mutated protein (ATM), ataxia telangiectasia and Rad3-related protein (ATR), and DNA-PKcs [12]. ATM is the primary activator and master controller of the cellular response to DNA DSBs and phosphorylates key players in the DNA damage response network to induce cell cycle arrest, apoptosis and DNA repair [13].

Recently, survivin was demonstrated to both suppress apoptosis and stimulate DNA repair. A higher incidence of DNA double-strand breaks after irradiation was observed, as indicated by a higher amount of Ser 139 phoshorylated histone $\gamma \mathrm{H} 2 \mathrm{AX}$ staining after survivin siRNA treatment or the transcriptional repressor YM155 $[14,15]$. The aim of this study was to examine the potential relationship between YM155 and DNA damage repair proteins in NSCLC cell lines.

\section{Methods and Materials}

\section{Cell culture}

We chose human A549 cell line according to the mRNA expression of human lung cancer cell lines in previous study. The A549 human NSCLC cell line was obtained from the Institute of Cancer Prevention and Treatment, Harbin Medical University. The cells were cultured in a 5\% $\mathrm{CO}_{2}$ atmosphere with 95\% humidity at $37^{\circ} \mathrm{C}$ in RPMI 1640 (Hyclone, Beijing, China) supplemented with 10\% bovine serum. YM155 (Astellas Pharma, Inc.) was dissolved in DMSO.

\section{KARGER}




\section{Cellular Physiology Cell Physiol Biochem 2015;37:1219-1230 \begin{tabular}{l|l} 
and Biochemisty $\begin{array}{l}\text { DOI: 10.1159/000430245 } \\
\text { Published online: September 30, } 2015\end{array}$ & $\begin{array}{l}\text { C 2015 S. Karger AG, Basel } \\
\text { www.karger.com/cpb }\end{array}$ \\
\hline
\end{tabular} \\ Hu et al.: The Mechanism of Radiosensitization by YM155}

\section{Subcellular fractionation}

Cytoplasmic and nuclear extracts were prepared according to the instructions of the NE-PER nuclear and cytoplasmic extraction kit (Pierce, Rockford, USA).

\section{Western blot}

The cells were washed twice with ice-cold PBS and then lysed in a solution containing $50 \mathrm{mM}$ Tris ( $\mathrm{pH}$ 7.4), $150 \mathrm{mM} \mathrm{NaCl}, 1 \% \mathrm{NP}-40,0.25 \%$ sodium deoxycholate, sodium orthovanadate, $1 \mathrm{mmol} / \mathrm{L}$ sodium fluoride, $1 \mathrm{mmol} / \mathrm{L}$ EDTA and $1 \mu \mathrm{g} / \mathrm{mL}$ leupeptin. The protein concentrations in the lysates were determined using Bradford reagent, and equal amounts of protein were separated by 12\% SDS-PAGE. The separated proteins were transferred to a nitrocellulose membrane, which was then exposed to $5 \%$ nonfat dried milk in TBST for 1 hour at room temperature before an overnight incubation at $4^{\circ} \mathrm{C}$ with rabbit monoclonal antibodies against human survivin (1:1000; Cell Signaling), human DNA-PKcs (1:100; Thermo Scientific), human Ku70 (1:5000; Epitomics), human ATM (1:5000; Epitomics), human phospho-specific S139 H2AX (1:1000; Cell Signaling), human phospho-specific T2609 DNA-PKcs (1:500; Abcam), human phosphospecific S2056 DNA-PKcs (1:5000; Epitomics), human phospho-specific S1981 ATM (1:1000; Cell Signaling), $\beta$-actin (1:2000; Santa Cruz Biotechnology), calnexin (1:1000; Cell Signaling), and lamin B1 (1:500; Cell Signaling). The membranes were washed with TBS containing 0.05\% Tween 20 before an $1 \mathrm{~h}$ incubation at room temperature with peroxidase-conjugated Affinipure Goat Anti-Rabbit IgG. Immune complexes were detected using an enhanced chemoluminescence detection system and autoradiography.

Clonogenic survival

The effectiveness of the combination of YM155 and ionizing radiation was determined using clonogenic assays. The NSCLC cells were treated with YM155 at the indicated concentration. After $48 \mathrm{~h}$, the cells were treated with various doses of ionizing radiation. Briefly, the cells were irradiated with $6 \mathrm{MeV}$ photons/100 $\mathrm{cm}$ focus-surface distance at a dose rate of $4.0 \mathrm{~Gy} / \mathrm{min}$ at room temperature in T-25 flasks. After treatment, the cells were trypsinized and counted. The cells were then washed with PBS and returned to the incubator to allow for macroscopic colony development. The colonies were counted after 14 days, and the plating efficiency and surviving fraction for each treatment were calculated based on the survival of non-irradiated cells treated with YM155 alone. The data were fitted into the classic single-hit multi-target model: SF=1-(1$\left.\mathrm{e}^{-\mathrm{D} / \mathrm{D} 0}\right)^{\mathrm{N}}$ to draw the dose-survival curve, from which the parameters(D0, Dq, N and SF2) representing the intrinsic cellular radiosensitivity were derived.

\section{Quantification of apoptosis}

To quantify the apoptotic tumor cells, fluorescein isothiocyanate (FITC)-labeled recombinant chicken Annexin V (MultiSciences Biotech Ltd, Hangzhou, China) was used in combination with propidium iodide (PI) to discriminate necrotic cells. Briefly, $10^{5}$ cells were resuspended in $500 \mu \mathrm{L}$ of Ringer's solution, incubated for 30 minutes at $4^{\circ} \mathrm{C}$ in the dark with $1 \mu \mathrm{g}$ AxV-FITC and $1 \mu \mathrm{g}$ PI, and analyzed on a Coulter EPICS XL flow cytometer with System XL II software.

\section{Cell cycle analysis}

Both adherent and detached A549 cells ( $\left.1 \times 10^{6} / \mathrm{ml}\right)$ were collected by trypsinization and washed with PBS for 10 minutes by centrifugation at $120 \mathrm{xg}$. The cells were resuspended in a hypertonic solution containing $50 \mu \mathrm{g} / \mathrm{mL}$ PI and $10 \mu \mathrm{g} / \mathrm{mL}$ RNaseA (Beyotime, Shanghai, China). Fluorescence-activated cell sorting (FACS) was performed using a Coulter EPICS XL flow cytometer (Coulter) and System XL II software.

\section{Immunoprecipitations}

Confluent cell cultures were irradiated as described above. Co-immunoprecipitations of nuclear extracts (500 $\mu \mathrm{g}$ diluted in $500 \mu \mathrm{L}$ Immunoprecipitation Incubation Buffer) were performed using the Nuclear Complex Co-IP kit (Active Motif) and Protein A Sepharose Fast Flow (Neomarkers, Fremont, CA) with antibodies against survivin $(1: 100 ; 71 G 4 B 7$, Cell Signaling, Danvers, MA), Ku70 (1:50; Epitomics, Burlingame, CA), DNA-PKcs (1:100; Neomarkers, Fremont, CA).

Immunofluorescence and the quantification of $\gamma$-H2AX foci

A549 cells were cultured on six-well slides and exposed to 4 Gy of radiation. At various times thereafter, the cells were fixed with $4 \%$ paraformaldehyde for $15 \mathrm{~min}$ at room temperature (RT). The 


\section{Cellular Physiology Cell Physiol Biochem 2015;37:1219-1230 \begin{tabular}{l|l} 
and Biochemistry $10.1159 / 000430245$ & $\begin{array}{l}\text { Doblished online: September 30, } 2015 \\
\text { Pus. Karger AG, Basel } \\
\text { www.karger.com/cpb }\end{array}$ \\
\hline
\end{tabular} \\ Hu et al.: The Mechanism of Radiosensitization by YM155}

cells were permeabilized with $0.25 \%$ Triton in PBS for 15 min and blocked with 3\% BSA for $1 \mathrm{~h}$ at room temperature. Subsequently, the cells were incubated with the following primary antibodies: anti-survivin (1:400; Cell Signaling), anti-DNA-PKcs (1:100; Neomarkers), phospho-specific S2056 DNA-PKcs (1:100; Epitomics) and anti-Ku70 (1:100; Cell Signaling). The immune complexes were visualized after incubation with the appropriate fluorescein- or TRITC-conjugated secondary antibody. The nuclei were counterstained with 4', 6-diamidino-2-phenylindole dihydrochloride (DAPI) (Invitrogen), the coverslips were mounted in fluorescence mounting medium, and the fluorescence was visualized using a confocal laser scanning microscope equipped with the LSM5 PASCAL system (Carl Zeiss). To quantify $\gamma$-H2AX foci, 300-500 nuclei were evaluated for each data point.

\section{Growth Inhibition Assay}

Cells were seeded at a density of $4 \times 10^{3}$ cells $/ 200 \mu \mathrm{L}$ in a 96-well microplate and cultured for 24 hours. The cells were treated sequentially with the drugs: each drug was added for 24 hours followed by 24 hours in drug-free growth medium. Control wells were treated similarly by aspirating the media at each 24 -hour time point. After 24, 48 or 72 hours at $37^{\circ} \mathrm{C}$, 3-(4, 5-methylthiazol-2-yl)-2, 5-diphenyl-tetrazolium bromide (MTT; $20 \mu \mathrm{L} /$ well of a $5 \mathrm{mg} / \mathrm{ml}$ solution in PBS) was added for 4 hours. The converted purple formazan dye was solubilized by adding $150 \mu \mathrm{L} /$ well of dimethyl sulfoxide and quantitated by measuring the absorbance at $570 \mathrm{~nm}$ with an enzyme-linked immunosorbent assay reader (HTS7000; Perkin Elmer, Rodgau, Germany) and HTS-Soft software (PerkinElmer).

\section{Results}

To determine the effect of YM155 on cell survival, we performed a clonogenic survival assay. YM155 down-regulated survivin expression in NSCLC cells in a concentration- and time-dependent manner. Drug treatment between 1 and $800 \mathrm{nmol} / \mathrm{L}$ for $48 \mathrm{~h}$ revealed that YM155 decreased A549 cell survival with a median inhibitory concentration (IC ${ }_{50}$ ) of 134 $\mathrm{nmol} / \mathrm{L}$. We ascertained the effect of YM155 on survivin expression in human NSCLC cells by immunoblot analysis. Treatment of A549 cells with $100 \mathrm{nmol} / \mathrm{L}$ YM155 for 2, 6, 12, 24 or $48 \mathrm{~h}$ decreased survivin expression in a time-dependent manner. Survivin expression in A549 cells decreased by $6 \mathrm{~h}$ and was virtually undetectable after $48 \mathrm{~h}$. Recently, transcription factors, such as $\mathrm{p} 53$, have been identified that regulate survivin expression in various human cancer cell lines [16, 17]. P53 is a transcription factor that induces apoptosis by regulating apoptotic genes. Survivin is targeted by p53 for down-regulation. p53 might induce apoptosis by antagonizing the anti-apoptotic activity of survivin. Therefore, we studied the effect of YM155 on the abundance of p53 in a NSCLC cell line. YM155 did not significantly affect p53 expression in A549 cells, suggesting that decreased survivin expression is independent of p53. Based on these data, we set $100 \mathrm{nmol} / \mathrm{L} \mathrm{YM155}$ for $48 \mathrm{~h}$ as the standard treatment for the radiation experiments.

\section{YM155-induced radiosensitization of NSCLC cells}

We investigated the effect of YM155 on the radiosensitivity of NSCLC cells. Treatment with $100 \mathrm{nmol} / \mathrm{L}$ YM155 for $48 \mathrm{~h}$ shifted the A549 survival curve to the left with a dose enhancement factor of 1.45, suggesting that YM155 increased the radiosensitivity of A549 cells (Fig. 1C).

\section{YM155 increased radiation-induced apoptosis in NSCLC cells}

We studied the effect of YM155 on radiation-induced apoptosis in A549 cells using flow cytometry. In A549 cells, the number of apoptotic cells at 24 and 48 hours was greater after treatment with both YM155 and radiation than the combined increases induced by YM155 or radiation alone (Fig. 2A). These data suggested that YM155 promoted radiation-induced apoptosis in NSCLC cells.

\section{KARGER}


Fig. 1. The effects of YM155 on survivin expression and the radiosensitivity of A549 cells. (A) Cells were treated with the indicated concentrations of YM155 for 48h and then assayed for clonogenic survival. The data points represent the mean from three independent experiments, and the bars represent the SD. (B) A549 cells were treated with $100 \mathrm{nmol} / \mathrm{L}$ YM155 for the indicated times, and cell lysates were subjected to immunoblot analysis with antibodies against survivin or p53. (C) Cells were treated with 100nmol/L YM155 or vehicle (control) for $48 \mathrm{~h}$ and subsequently irradiated with 2-10Gy of ionizing radiation. After 10-14 days, the cells were fixed and stained. The surviving fractions were calculated based on colony counts and plating efficiency. Each value represents the mean of three independent experiments.

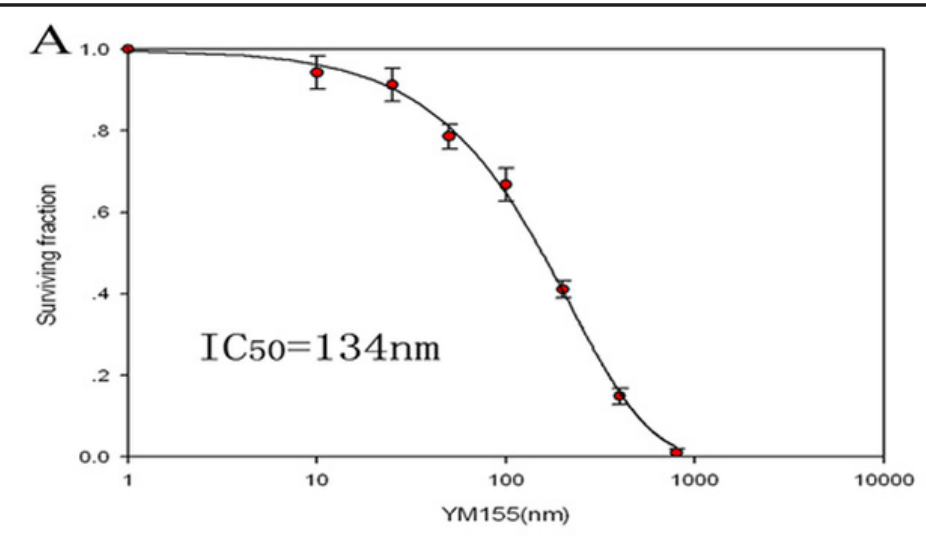

B Time with 100nm YM155(h)

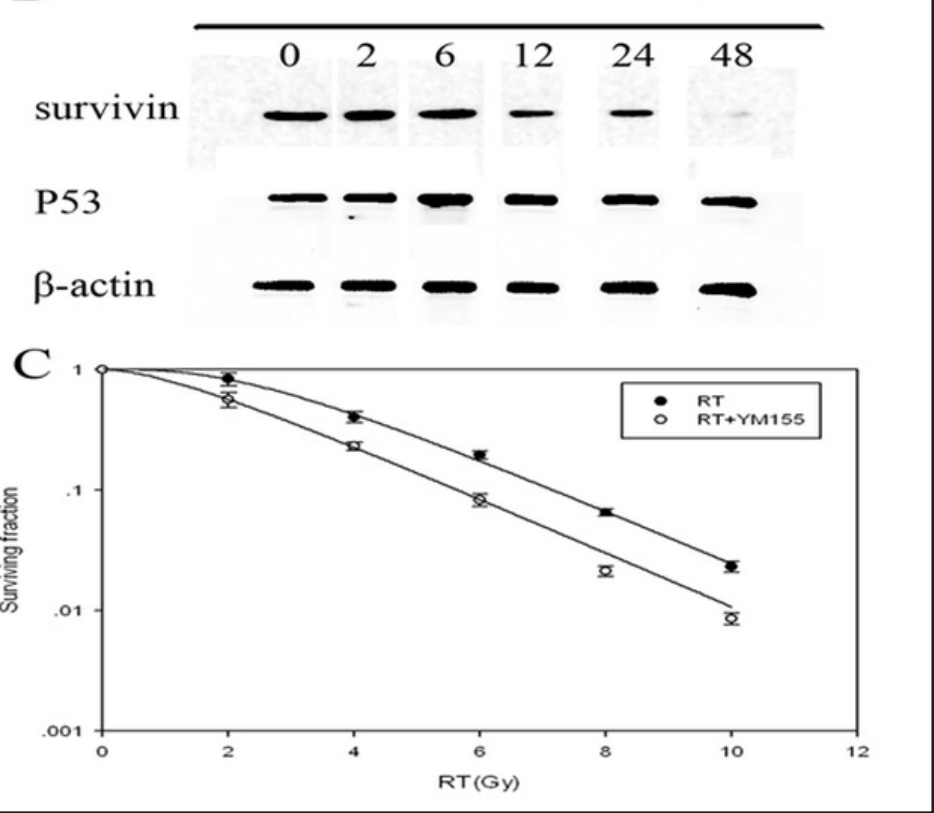

Cell cycle analysis

Cell cycle analyses were performed 24 hours after YM155 treatment. These analyses revealed an increase in the G2/M fraction in YM155-treated A549 cells, indicating that a larger fraction of the treated cells remained in a more radiosensitive stage of the cell cycle compared with the control cells (Fig. 2B).

\section{Nuclear import of survivin after irradiation}

To determine the mechanism for YM155-induced radiosensitization of A549 cells, we sought to identify alterations in survivin protein after irradiation. In non-irradiated A549 cells, survivin was predominantly cytoplasmic. After irradiation, immunoblotting demonstrated a rapid increase in nuclear survivin that paralleled a decrease in cytoplasmic survivin. The total survivin level did not change up to $60 \mathrm{~min}$ after irradiation, indicating a translocation or accumulation event rather than increased protein expression (Fig. 3A). Immunofluorescence experiments confirmed the increased nuclear localization of survivin after irradiation (Fig. 3B).

YM155 inhibited DNA repair in irradiated NSCLC cells

The induction of DNA DSBs and DNA repair was studied by detecting H2AX serine 139 phosphorylation at $0,30,60,120,240$ and $360 \mathrm{~min}$ after irradiation, by quantifying the 

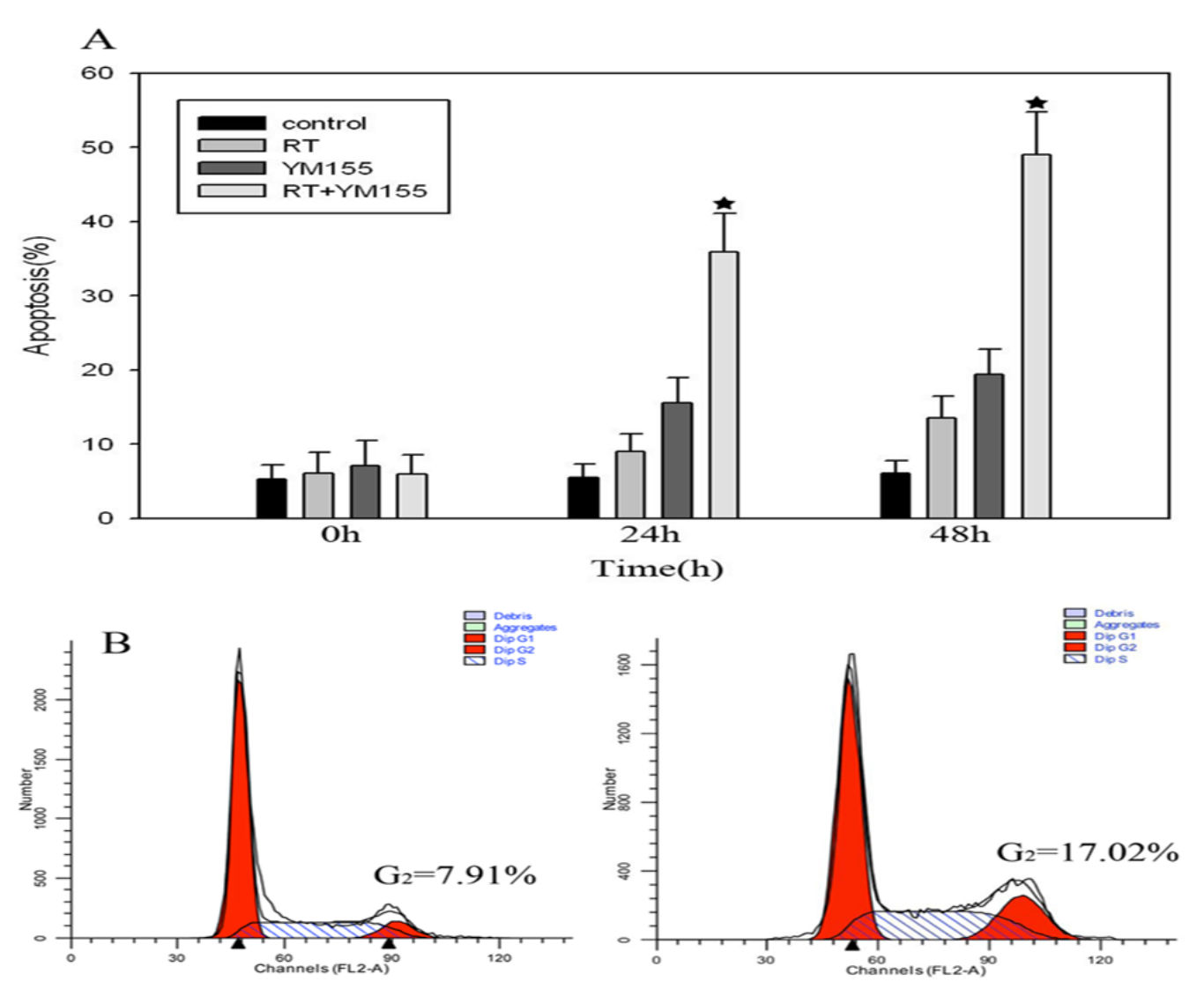

Fig. 2. The effect of YM155 on radiation-induced apoptosis and cell cycle distribution in A549 cells. (A) Cells were treated with $100 \mathrm{nmol} / \mathrm{L}$ YM155 or vehicle for $48 \mathrm{~h}$ with or without $4 \mathrm{~Gy}$ of radiation and then incubated in drug-free medium for 24 and $48 \mathrm{~h}$, at which time the percentage of apoptotic cells was determined by flow cytometry; the bars represent the SD. ${ }^{*} \mathrm{P}<0.05$ versus radiation or YM155 alone. (B) Cells were treated with 100nmol/L YM155 or vehicle for $48 \mathrm{~h}$ and then incubated in drug-free medium for $24 \mathrm{~h}$. Fixed A549 cells were labeled with propidium iodide (PI), and flow cytometry was utilized to measure DNA content. The percentage of cells in G2/M are shown in the individual plots. The data are from a representative experiment $(n=3)$.

formation of $\gamma$-H2AX foci at $0,30,60,120,240$ and 360 min and by monitoring residual $\gamma$-H2AX foci $24 \mathrm{~h}$ after irradiation. The formation of $\gamma$-H2AX foci in A549 cells was apparent between 30 minutes and 6 hours after irradiation. Compared with control-treated cells, phosphohistone H2AX levels increased after survivin levels decreased in YM155-treated A549 cells 30 min after irradiation (Fig. 4A). In the presence of YM155 $24 \mathrm{~h}$ after irradiation, these foci revealed that YM155 significantly inhibited DSB repair. Between 30 and 360min after irradiation, phospho-histone H2AX increased subsequent to the YM155-induced decrease in survivin expression compared with radiation alone (Fig. 5). These results suggested that the down-regulation of survivin expression by YM155 inhibited the repair of radiation-induced DSBs in NSCLC cells, potentially accounting for the observed radiosensitization by this drug.

\section{Survivin formed a complex with Ku70 and DNA-PKcs}

The recruitment of repair proteins to DSBs constitutes the primary event that is triggered by DNA damage $[10,18]$. To determine whether survivin interacted with the DNA DSB repair machinery, we performed co-immunoprecipitation and immunofluorescence experiments. Nuclear extracts that were obtained at $0,30,60,120$, or 360 min after irradiation were immunoprecipitated with an anti-survivin, anti-DNA-PKcs, or anti-Ku70 
Fig. 3. Survivin expression in the nucleus and cytoplasm after irradiation. (A) A549 cells were irradiated with 4Gy, and either total protein or cytoplasmic and nuclear protein fractions were isolated. Survivin was detected by western blotting at the indicated times post-irradiation. Non-irradiated cells and $\beta$-actin, calnexin (cytoplasm) or lamin B1 (nucleus) served as controls. (B) Survivin localization was analyzed by fluorescent microscopy $1 \mathrm{~h}$ after irradiation with 4Gy (upper panel) using an anti-survivin primary antibody and a Fluorescein-conjugated secondary antibody (green). DNA was counterstained with 4', 6-diamidino-2-phenylindole dihydrochloride (DAPI) (blue). Non-irradiated cells served as the control (upper panel). The presented data are from one representative experiment $(\mathrm{n}=3)$. Scale bar: $10 \mu \mathrm{m}$.

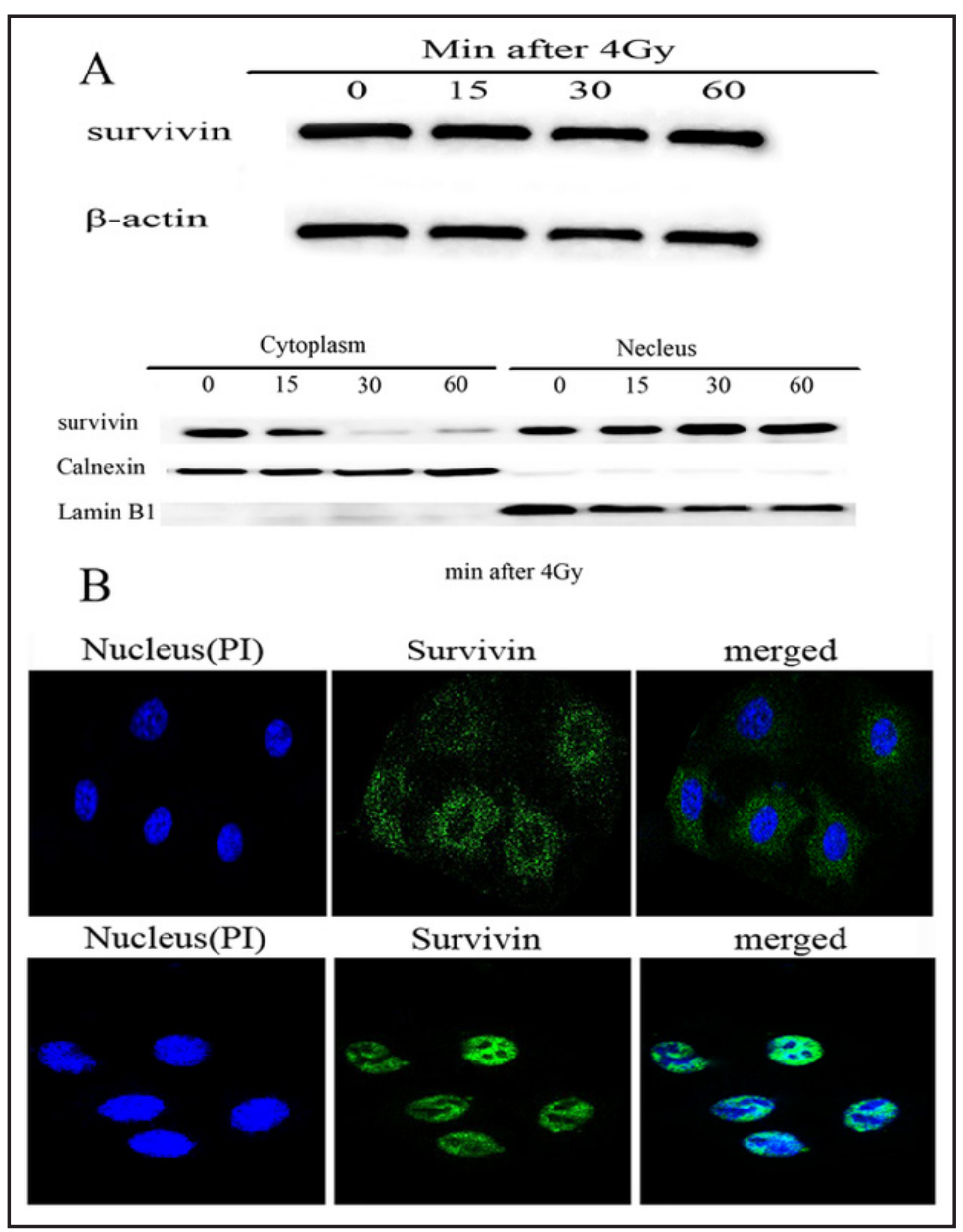

antibody, and the associated proteins were visualized by Western blotting. DNA-PKcs, Ku70 co-immunoprecipitated with endogenous survivin (Fig. 6A). Reverse precipitations using Ku70 and DNA-PKcs antibodies confirmed the formation of a survivin, DNA-PKcs and Ku70 complex. For dual immunofluorescent labeling, A549 cells were fixed and incubated with an anti-survivin antibody and a Fluorescein-conjugated secondary antibody (green) or with an anti Ku70, anti-DNA-PKcs or anti-phospho-specific S2056 DNA-PKcs antibody and a TRITCconjugated secondary antibody (red). The merged immunofluorescent microscopic images indicated that endogenous survivin colocalized with Ku70 and DNA-PKcs within distinct nuclear foci (Fig. 6B).

\section{YM155 altered DNA-PKcs kinase activity}

Additional experiments were performed to determine which aspects of molecular repair were altered in YM155-treated cells. Immunoblotting demonstrated that YM155 pretreatment affected the extent of nuclear DNA-PKcs phosphorylation at T2609 and S2056. At 60 min after irradiation, we observed decreased phosphorylation of DNA-PKcs at T2609. This suggested that decreased survivin expression in response to YM155 did not affect early T2609 phosphorylation. Compared with control cells, DNA-PKcs S2056 phosphorylation was decreased at 30,60,120 and 360 min after irradiation, further suggesting diminished DNA-PKcs kinase activity after the attenuation of survivin expression (Fig. 5).

\section{Discussion}

YM155 is a small molecule that specifically inhibits survivin expression in various cancer cell lines in vitro [8]. Clonogenic survival assays, the most reliable approach for determining 
Fig. 4. The effect of YM155 on the radiation-induced formation of $\gamma$-H2AX foci in A549 cells. (A) A549 cells were treated with vehicle or 100nmol/L YM155 for $48 \mathrm{~h}$ and then exposed to $4 \mathrm{~Gy}$ of radiation. After incubating in drug-free medium for the indicated time, the cells were fixed and subjected to immunofluorescent staining for $\gamma$-H2AX (green). Scale bar: $10 \mu \mathrm{m}$. (B) After irradiating A549 cells with 4Gy, the kinetics of $\gamma-\mathrm{H} 2 \mathrm{AX}$ foci formation were visualized using a $\gamma$-H2AX antibody, a fluorescein-conjugated secondary antibody, and 4',6-dia midi n o-2-phenylindole dihydrochloride (DAPI, nuclear counterstain). For each data point, 300-500 nuclei were evaluated; the bars represent the $\mathrm{SD}$. ${ }^{*} \mathrm{P}<0.05$ versus radiation or YM155 alone.

Fig. 5. The effect of YM155 on DNA damage repair proteins. A549 cells were treated with vehicle or 100nmol/L YM155 for 48 $\mathrm{h}$ and then exposed to $4 \mathrm{~Gy}$ of radiation. After incubating for the indicated times in drug-free medium, the cells were collected and subjected to immunoblotting. Representative results from at least three experiments are presented.
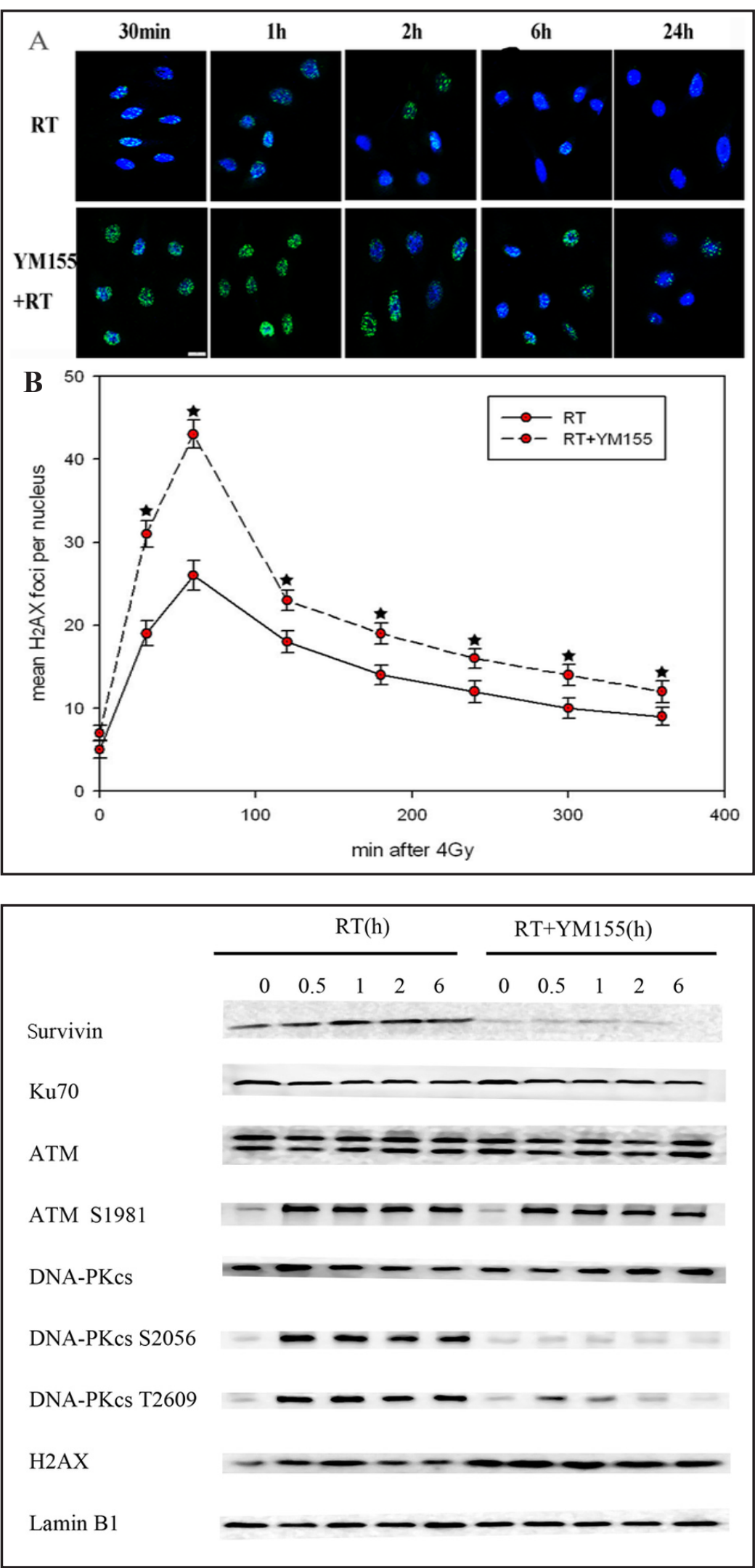

the ability of genotoxic agents to induce cell death, revealed that YM155 significantly potentiated the radiation-induced decrease in NSCLC cell survival. At 24 and 48 hours, 
Fig. 6. Immunoprecipitation and immunofluorescent staining of survivin and DNA damage repair proteins. (A) The nuclear protein fraction was isolated from A549 cells at the indicated time points after irradiation with 4Gy. Survivin was immunoprecipitated (IP) using anti-survivin antibodies, and the associated proteins were detected by Western blotting. To confirm an association, anti-Ku70, anti-DNA-PKcs antibodies were utilized in reverse IP and WB experiments to detect survivin. Representative results from at least three experiments are presented. (B) Immunofluorescent images of representative A549 cells stained for survivin(Fluorescein, green), DNA-PKcs(Rhodamine, red), Ku70 (Rhodamine, red), phospho-S2056 DNA-PKcs (Rhodamine; red), and DNA (DAPI, blue) $1 \mathrm{~h}$ after irradiation with 4Gy. Scale bar: $10 \mu \mathrm{m}$.

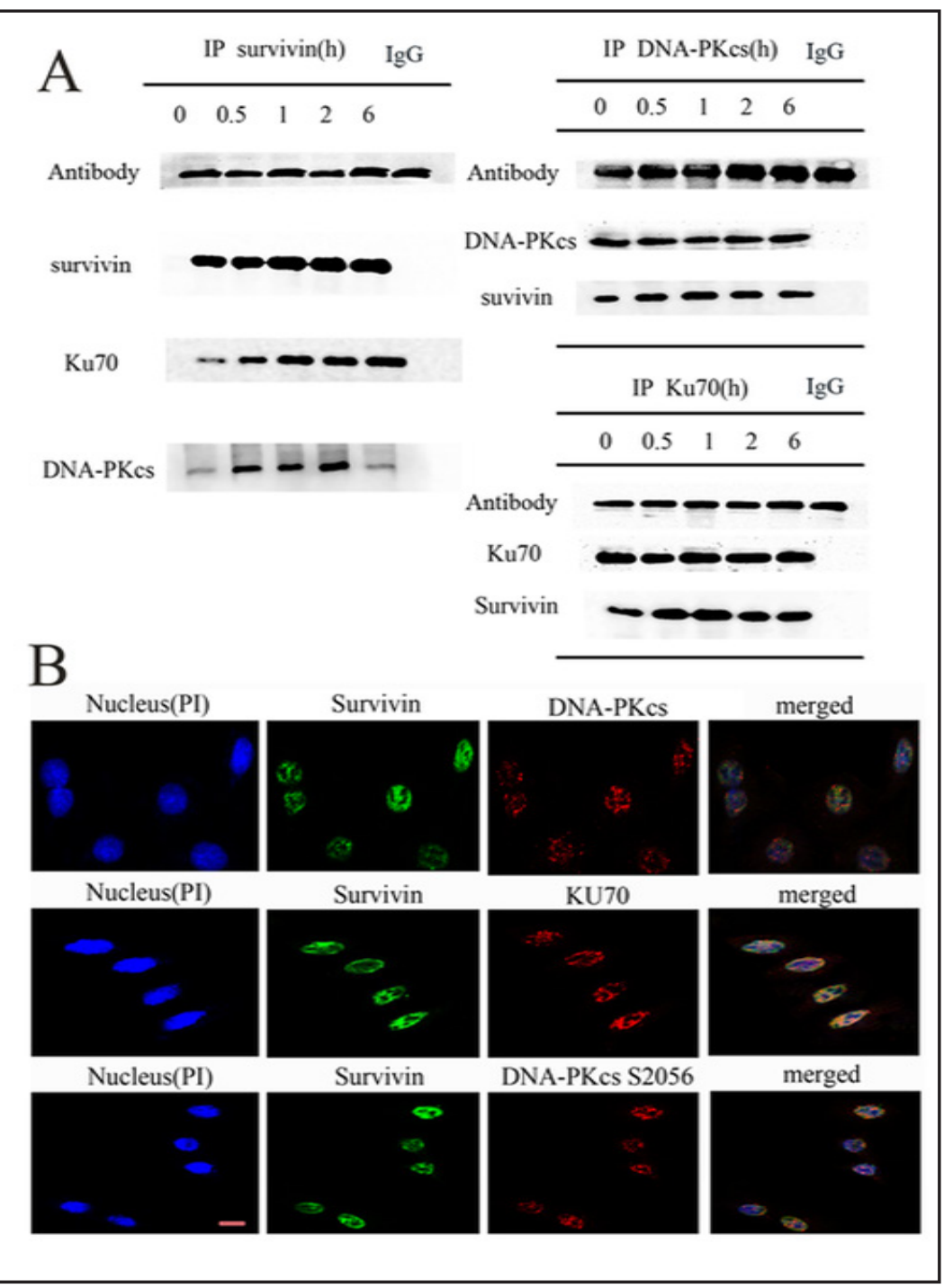

there were more apoptotic cells than in the YM155- and radiation-alone treatment groups combined. Cell cycle analyses revealed an increase in the $G_{2} / M$ fraction in YM155-treated cells, indicating that a larger fraction of the treated cells remained in a more radiosensitive stage of the cell cycle compared with the control cells. Our findings suggested that YM155 sensitized tumor cells to radiation in part by enhancing radiation-induced apoptosis and increasing the fraction of cells in G2/M. However, our data indicated that this sensitization might also result from diminished DNA repair, and the repair of DNA double-strand breaks is considered to be a critical event.

Recently, the understanding of survivin function has been bolstered by the observation that survivin is present in distinct subcellular pools, including the nucleus, cytoplasm, and mitochondria [19-21]. The subcellular distribution of survivin plays an important role in its ability to regulate cell division and survival. Whereas the cytoplasm localization of survivin and its release from mitochondria are considered to be cytoprotective because this supports its anti-apoptotic activity [22], the nuclear localization of survivin is linked to cell division because it is a subunit of the chromosomal passenger complex (CPC) [23]. A leucine-rich nuclear export signal (NES) has been described, and recent data indicate that the interaction of the NES with the nuclear export receptor chromosome region maintenance protein 1 homolog (Crm1) is critical for the intracellular localization of survivin and for its cancerrelated functions [24-26]. Importantly, subcellular protein compartmentalization plays a 
role in the radiation response, as export-deficient NES mutants failed to protect tumor cells against radiation-induced apoptosis [27]. DNA damage by ionizing radiation stimulates a rapid discharge of the mitochondrial pool of survivin into the cytosol, preserving the viability of tumor cells during a protracted G2 arrest by antagonizing DNA damage-induced apoptosis [28]. Therefore, one unresolved question is how survivin gains access to the nucleus after irradiation. Although at $16.5 \mathrm{kDa}$ survivin is small enough to enter the nucleus by diffusion, the rapid radiation-induced nuclear accumulation without increased expression of survivin argues against a passive process and favors a shuttle mechanism [29]. Notably, recent co-immunoprecipitation experiments performed by Li et al. [30] revealed that glycogen synthase kinase- 3 beta (GSK3- $\beta$ ) binds to survivin. After stress-induced activation of GSK3- $\beta$, survivin translocates from the cytoplasm to the nucleus. Although this was not addressed in our study, GSK3- $\beta$ may be a putative nuclear shuttling partner for survivin after irradiation.

$\mathrm{H} 2 \mathrm{AX}$ phosphorylation is a signal for the accumulation of repair proteins in the vicinity of damaged chromatin [12], and a linear relationship exists between the number of $\gamma$-H2AX foci and DSBs [31]. The number of $\gamma-\mathrm{H} 2 \mathrm{AX}$ foci is therefore a sensitive and specific indicator of the existence of DSBs, with a decrease in foci reflecting DSB repair. We demonstrated that YM155 inhibited the repair of radiation-induced DSBs in NSCLC cells. We observed increased $\mathrm{H} 2 \mathrm{AX}$ phosphorylation and the formation of nuclear foci 30-360 min after irradiation as well as a significant increase in the persistence of residual $\gamma$-H2AX foci $24 \mathrm{~h}$ after survivin knock-down. If left unrepaired, DSBs can lead to chromosome loss or cell death; therefore, agents that inhibit DSB repair increase the sensitivity of cells to ionizing radiation [31, 32]. Our results suggested that the inhibition of DSB repair by YM155 contributed to the radiosensitization induced by this drug. Decreased survivin expression impaired the repair of radiation-induced DNA damage [29], and our results suggested that the YM155-induced inhibition of DNA repair was attributable to the down-regulation of survivin expression. After irradiation, we observed the formation of survivin foci with similar kinetics and numbers as $\gamma \mathrm{H} 2 \mathrm{AX}$ foci. DNA repair resulted in the disappearance of survivin foci, which indicated that survivin was involved in the formation of DNA repair complexes at sites of DNA damage.

To further elucidate the mechanistic role of survivin in DNA DSB repair, we determined whether survivin physically interacted with members of the DNA DSB repair machinery. In this study, we demonstrated the direct involvement of survivin in DNA DSB repair. After irradiation, the rapid nuclear accumulation of survivin and its interactions with NHEJ repair proteins (DNA-PKcs and Ku70) were shown by co-immunoprecipitation. In mammalian cells, the efficient and successful repair of radiation-induced DNA-DSB is primarily achieved by non-homologous end joining, in which DNA-PKcs is one of the critical proteins. Targeting of DNA-PKcs by siRNA or antisense [33, 34] increases residual DSBs and cellular radiosensitivity. Our results indicated that the nuclear translocation of survivin and its direct interaction with DNA-PKcs were necessary for successful DNA DSB repair. Immunoblotting revealed that YM155 pretreatment altered the amount of nuclear DNA-PKcs phosphorylation at T2609 and S2056 but that the YM155-mediated decrease in survivin expression did not affect early T2609 phosphorylation. However, a recent study showed that ATM kinase may phosphorylate DNA-PKcs at residue 2609 in vivo [35]. YM155 pretreatment inhibited autophosphorylation at S2056.

In this study, we identified a direct connection between survivin and DNA DSB repair. After irradiation, survivin rapidly accumulated in the nucleus and formed a complex with NHEJ repair proteins (DNA-PKcs and Ku70). Furthermore, there was a greater incidence of DNA DSBs in response to irradiation after YM155 decreased survivin expression, as indicated by the increased phosphorylation of histone H2AX at serine 139 and the increased formation of nuclear foci. Although the function of survivin in the repair complex was not explored in detail, part of its role may relate to the diminished autophosphorylation of DNA-PKcs at serine 2056. 


\section{Acknowledgements}

We are grateful to Dr. Hongfei Ji and Dr. Yuyan Ma at the Institute of Cancer Prevention and Treatment, Harbin Medical University. Songliu Hu was supported by Heilongjiang provincial Health Department fund at the Third Affiliated Hospital of Harbin Medical University (2014350), and Xiangying Xu was supported by Heilongjiang Provincial Science and Technology projects (WB12C101) and Special Fund for Innovative Talent in Science and Technology Research of Harbin (2012RFXXS063).

\section{Disclosure Statement}

We have no conflicts of interest to declare.

\section{References}

1 Huang RY, Chu YL, Jiang ZB, Chen XM, Zhang X, Zeng X: Glycyrrhizin suppresses lung adenocarcinoma cell growth through inhibition of thromboxane synthase. Cell Physiol Biochem 2014;33:375-388.

2 Rodel F, Reichert S, Sprenger T, Gaipl US, Mirsch J, Liersch T, Fulda S, Rodel C: The role of survivin for radiation oncology: moving beyond apoptosis inhibition. Curr Med Chem 2011;18:191-199.

3 Church DN, Talbot DC: Survivin in solid tumors: rationale for development of inhibitors. Curr Oncol Rep 2012;14:120-128.

4 Chakravarti A, Zhai GG, Zhang M, Malhotra R, Latham DE, Delaney MA, Robe P, Nestler U, Song Q Loeffler J: Survivin enhances radiation resistance in primary human glioblastoma cells via caspase-independent mechanisms. Oncogene 2004;23:7494-7506.

5 Cheson BD, Bartlett NL, Vose JM, Lopez-Hernandez A, Seiz AL, Keating AT, Shamsili S, Papadopoulos KP: A phase II study of the survivin suppressant YM155 in patients with refractory diffuse large B-cell lymphoma. Cancer 2012;118:3128-3134.

6 Tolcher AW, Quinn DI, Ferrari A, Ahmann F, Giaccone G, Drake T, Keating A, de Bono JS: A phase II study of YM155, a novel small-molecule suppressor of survivin, in castration-resistant taxane-pretreated prostate cancer. Ann Oncol 2012;23:968-973.

7 Lewis KD, Samlowski W, Ward J, Catlett J, Cranmer L, Kirkwood J, Lawson D, Whitman E, Gonzalez R: A multi-center phase II evaluation of the small molecule survivin suppressor YM155 in patients with unresectable stage III or IV melanoma. Invest New Drugs 2011; 29:161-166.

8 Giaccone G, Zatloukal P, Roubec J, Floor K, Musil J, Kuta M, van Klaveren RJ, Chaudhary S, Gunther A, Shamsili S: Multicenter phase II trial of YM155, a small-molecule suppressor of survivin, in patients with advanced, refractory, non-small-cell lung cancer. J Clin Oncol 2009;27:4481-4486.

9 Tolcher AW, Mita A, Lewis LD, Garrett CR, Till E, Daud AI, Patnaik A, Papadopoulos K, Takimoto C, Bartels P, Keating A, Antonia S.: Phase I and pharmacokinetic study of YM155, a small-molecule inhibitor of survivin. J Clin Oncol 2008;26:5198-5203.

10 Valerie K, Povirk LF: Regulation and mechanisms of mammalian double-strand break repair. Oncogene 2003;22:5792-5812.

11 Lees-Miller SP, Meek K: Repair of DNA double strand breaks by non-homologous end joining. Biochimie 2003;85:1161-1173.

12 Celeste A, Fernandez-Capetillo 0, Kruhlak MJ, Pilch DR, Staudt DW, Lee A, Bonner RF, Bonner WM, Nussenzweig A: Histone H2AX phosphorylation is dispensable for the initial recognition of DNA breaks. Nat Cell Biol 2003;5:675-679.

13 Shiloh Y: ATM and related protein kinases: safeguarding genome integrity. Nat Rev Cancer 2003;3:155-168.

14 Rodel F, Hoffmann J, Distel L, Herrmann M, Noisternig T, Papadopoulos T, Sauer R, Rodel C: Survivin as a radioresistance factor, and prognostic and therapeutic target for radiotherapy in rectal cancer. Cancer Res 2005;65:4881-4887.

15 Iwasa T, Okamoto I, Suzuki M, Nakahara T, Yamanaka K, Hatashita E, Yamada Y, Fukuoka M, Ono K, Nakagawa K: Radiosensitizing effect of YM155, a novel small-molecule survivin suppressant, in non-small cell lung cancer cell lines. Clin Cancer Res 2008;14:6496-6504.

16 Hoffman WH, Biade S, Zilfou JT, Chen J, Murphy M: Transcriptional repression of the anti-apoptotic survivin gene by wild type p53. J Biol Chem 2002;277:3247-3257. 
17 Mirza A, McGuirk M, Hockenberry TN, Wu Q Ashar H, Black S, Wen SF, Wang L, Kirschmeier P, Bishop WR, Nielsen LL, Pickett CB, Liu S: Human survivin is negatively regulated by wild-type p53 and participates in p53-dependent apoptotic pathway. Oncogene 2002;21:2613-2622.

18 Riches LC, Lynch AM, Gooderham NJ: Early events in the mammalian response to DNA double-strand breaks. Mutagenesis 2008;23:331-339.

19 Dohi T, Xia F, Altieri DC: Compartmentalized phosphorylation of IAP by protein kinase A regulates cytoprotection. Mol Cell 2007;27:17-28.

20 Fortugno P, Wall NR, Giodini A, O'Connor DS, Plescia J, Padgett KM, Tognin S, Marchisio PC, Altieri DC: Survivin exists in immunochemically distinct subcellular pools and is involved in spindle microtubule function. J Cell Sci 2002;115:575-585.

21 Dohi T, Beltrami E, Wall NR, Plescia J, Altieri DC: Mitochondrial survivin inhibits apoptosis and promotes tumorigenesis. J Clin Invest 2004;114:1117-1127.

22 Stauber RH, Mann W, Knauer SK: Nuclear and cytoplasmic survivin: molecular mechanism, prognostic, and therapeutic potential. Cancer Res 2007;67:5999-6002.

23 Connell CM, Colnaghi R, Wheatley SP: Nuclear survivin has reduced stability and is not cytoprotective. J Biol Chem 2008;283:3289-3296.

24 Stauber RH, Rabenhorst U, Rekik A, Engels K, Bier C, Knauer SK: Nucleocytoplasmic shuttling and the biological activity of mouse survivin are regulated by an active nuclear export signal. Traffic 2006;7:14611472.

25 Colnaghi R, Connell CM, Barrett RM, Wheatley SP: Separating the anti-apoptotic and mitotic roles of survivin. J Biol Chem 2006;281:33450-33456.

26 Knauer SK, Bier C, Habtemichael N, Stauber RH: The Survivin-Crm1 interaction is essential for chromosomal passenger complex localization and function. EMBO Rep 2006;7:1259-1265.

27 Knauer SK, Kramer OH, Knosel T, Engels K, Rodel F, Kovacs AF, Dietmaier W, Klein-Hitpass L, Habtemichael N, Schweitzer A, Brieger J, Rödel C, Mann W, Petersen I, Heinzel T, Stauber RH: Nuclear export is essential for the tumor-promoting activity of survivin. FASEB J 2007;21:207-216.

28 Ghosh JC, Dohi T, Raskett CM, Kowalik TF, Altieri DC: Activated checkpoint kinase 2 provides a survival signal for tumor cells. Cancer Res 2006;66:11576-11579.

29 Capalbo G, Dittmann K, Weiss C, Reichert S, Hausmann E, Rodel C, Rodel F: Radiation-induced survivin nuclear accumulation is linked to DNA damage repair. Int J Radiat Oncol Biol Phys 2010;77:226-234.

30 Li J, Xing M, Zhu M, Wang X, Wang M, Zhou S, Li N, Wu R, Zhou M: Glycogen synthase kinase 3beta induces apoptosis in cancer cells through increase of survivin nuclear localization. Cancer Lett 2008;272:91-101.

31 Banath JP, Macphail SH, Olive PL: Radiation sensitivity, H2AX phosphorylation, and kinetics of repair of DNA strand breaks in irradiated cervical cancer cell lines. Cancer Res 2004;64:7144-7149.

32 Taneja N, Davis M, Choy JS, Beckett MA, Singh R, Kron SJ, Weichselbaum RR: Histone H2AX phosphorylation as a predictor of radiosensitivity and target for radiotherapy. J Biol Chem 2004;279:2273-2280.

33 Peng Y, Zhang Q Nagasawa H, Okayasu R, Liber HL, Bedford JS: Silencing expression of the catalytic subunit of DNA-dependent protein kinase by small interfering RNA sensitizes human cells for radiation-induced chromosome damage, cell killing, and mutation. Cancer Res 2002;62:6400-6404.

34 Marangoni E, Foray N, O'Driscoll M, Douc-Rasy S, Bernier J, Bourhis J, Jeggo P: A Ku80 fragment with dominant negative activity imparts a radiosensitive phenotype to CHO-K1 cells. Nucleic Acids Res 2000;28:4778-4782.

35 Chen BP, Uematsu N, Kobayashi J, Lerenthal Y, Krempler A, Yajima H, Lobrich M, Shiloh Y, Chen DJ: Ataxia telangiectasia mutated (ATM) is essential for DNA-PKcs phosphorylations at the Thr-2609 cluster upon DNA double strand break. J Biol Chem 2007;282:6582-6587. 